\title{
The attitude and perception about need of WPBA in Dental education among the senior faculties of Dental Institutes of Central India- cross-sectional study
}

\author{
Varsha S Manekar \\ Associate Professor, Dept. Oral \& Maxillofacial Surgery, Government Dental College \& Hospital, Nagpur, Maharashtra, India
}

*Corresponding Author: Varsha S Manekar

Email: varsha@manekar.info

\begin{abstract}
Context: WPBAs are designed to assess a clinician's performance on a day-to-day basis in real life working conditions. In dentistry the undergraduates and postgraduates learn basic as well as complex procedural skills. The formative assessment is also a part of process. The group of assessments WPBA are the structured assessments with feedback can be used for these formative assessments.

Aims: AIM of this research is "To Assess attitude and perception about need of WPBA in Dental education among the senior faculties of Dental Institutes in central India."

Settings and Design: The study design was cross-sectional survey. This study was conducted in the department of oral \& maxillofacial surgery at GDCH, Nagpur. The participants were the senior faculties of clinical subjects with experience of teaching more than five years.

Materials and Methods: A cross-sectional survey was sent on line to the senior dental faculties of central India.

Results: 64\% participants were aware of the WPBA, 36\% were unaware of it. The source of knowledge about 51.4\% from HSET workshops; $22.9 \%$ from literature: $11.4 \%$ from studies conducted in their department. $70 \%$ participants responded that WPBA is not used in their department, rest responded that it is used.

Conclusions: The results from this survey confirms the positive attitude of the dental faculties towards WPBA. The perception of participants is it will be useful tool for UG as well as PG formative assessment.
\end{abstract}

Keywords: WPBA, Formative assessment, DOPS, Mini Cex, Dental faculties.

Workplace-based assessment (WPBA) is a relatively new concept in dental training in our colleges. WPBA has been defined as the 'assessment of day-to-day practices undertaken in the working environment'. WPBAs are designed to assess a clinician's performance on a day-to-day basis in real life working conditions.

In dentistry the undergraduates and postgraduates learn basic as well as complex procedural skills. The formative assessment is also a part of process. The group of assessments WPBA are the structured assessments with feedback can be used for these formative assessments. The advantages of WPBA as mentioned by Norcini ${ }^{1}$ include.

1. They offer a formative assessment tool by offering information about one's actual performance in the workplace rather than in the artificial environment of a summative examination.

2. They complement the more traditional examinationbased assessment of knowledge and thus afford a more holistic and comprehensive assessment of trainees' progress.

3. They provide an opportunity to improve training and facilitate interaction with the trainee but they also, ultimately, aim to improve patient care.

4. Its particular strength lies in the rich variety of feedback it offers.

5. This is a competency-based system, intended to identify areas for improvement in the individual trainee, on the basis of supportable and documented evidence.

The assessment tools ${ }^{2}$ are -

(a) Mini-Clinical Evaluation Exercise (mini-CEX): The skills assessed are history taking, physical examination, diagnostic, clinical judgement, decision making, communication and time management.

(b) Direct Observation of Procedural Skills (DOPS): This assessment skill focuses on evaluating procedural skill of students.

(c) Blinded Patient Encounters (BPE): Students, in groups of 4-5, participate in a bedside tutorial. It starts with a period of direct observation in which one of the students in the group is observed performing a focused interview or physical examination as instructed by the clinician educator conducting the teaching session. Thereafter the student is expected to provide a diagnosis, including a differential diagnosis, based on the clinical findings.

(d) Case-based Discussion (CbD): Discussion of clinical cases - These are semi-structured discussions known as case-based discussions (CbDs) regarding the management of a patient treated or seen by the trainee, for example during a consultation clinic.

In a review article on WPBA in dental education author ${ }^{2}$ has mentioned that it is a strong tool if used properly definitely result in improvement of the dental trainee's competency.

As mentioned by Tejinder Singh ${ }^{3}$ et al There has been an increasing emphasis on defining outcomes of medical education in terms of 'performance' of trainees. This is a step beyond the description of outcomes in terms of 'competence' that encompasses mostly 'potential abilities' rather than the 'actual performance'. The contextual adaptations and behaviour judgments of the trainees are best assessed by a program of in-training assessment.

In contrast to the medical education competency based curriculum is not a part of dental education. The implementation of new methods of Teaching- Learning and 
assessment tools are at preliminary level. These need shift of teaching from teaching centric to student centric. The training and voluntary involvement of dental teachers in new methods of WPBA is the need of new age dental teaching. All over world the dental universities are using these for the benefit of the students and better dental clinicians. "Are our dental teachers aware of WPBA?" "what is their attitude towards it?" - needs to be evaluated. Hence this cross-sectional survey was conducted.

AIM of this research is "To Assess attitude and perception about need of WPBA in Dental education among the senior faculties of Dental Institutes in central India."

\section{Materials and Methods}

The study design was cross-sectional survey. This study was conducted in the department of oral \& maxillofacial surgery at GDCH, Nagpur. The participants were the senior faculties of clinical subjects with experience of teaching more than five years. The approval from institutional ethics committee was taken. The information about the WPBA is also conveyed to the participants through a document. The development of the questionnaire was done by the author. The three experts colleagues, fellows of Foundation of advancement in international medical education and research (FAIMER) did the content and face validity of the survey tool (questionnaire). An online survey sent to 78 teachers through google forms, fifty of them responded in time. These google forms were sent through a link via e-mail or what's ap massage. Only fifty participants responded so the Sample size is fifty numbers. The observations are evaluated by mean, median and descriptive statistics. The survey tool is attached here.

\section{Observations and Result}

1. $64 \%$ participants were aware of the WPBA, $36 \%$ were unaware of it.

2. The source of knowledge about $51.4 \%$ from HSET workshops; $22.9 \%$ from literature: $11.4 \%$ from studies conducted in their department.

3. Fig. 1 shows the response of the most suitable type for the dental faculty DOPS (53.3\%); minicex (48.9\%); CbD $(37.8 \%)$; MSF $(24.4 \%)$ and BPE (17.8\%).

4. $70 \%$ participants responded that WPBA is not used in their department, rest responded that it is used.

5. Fig. 2 shows opinion about feasibility- $40 \%$ disagreed to that WPBA is time consuming \& may not be feasible; $34.7 \%$ were neutral about it.

6. About teachers cooperation for using WPBA in Fig. 3: equal responses to the option of agree $(32.7 \%)$, maybe $(34.7 \%)$, \& disagree $(28.6 \%)$.

7. $25 \%$ participants agreed that students may like WPBA as per Fig. 4.

8. Fig. 5 shows $26 \%$ agree that it is useful for Undergraduate assessment.

9. Fig. 6 shows, $36 \%$ strongly agree $32 \%$ agree for the benefit of WPBA for postgraduates.

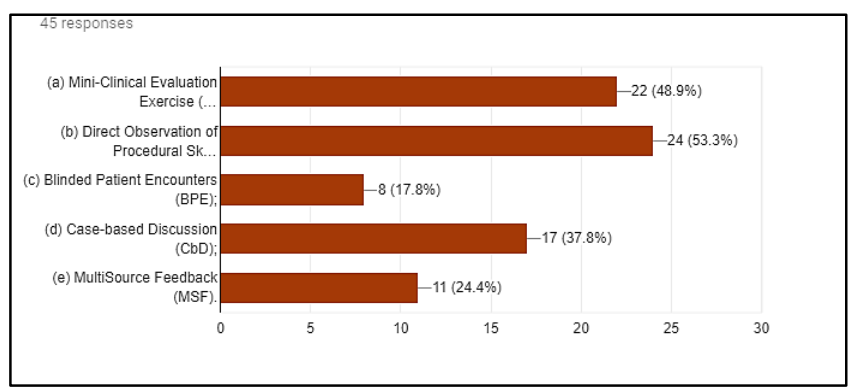

Fig. 1: Response of question 3 - Which of the following WPBA is suitable for your clinical setup or subject. Vertical axis (Y axis) shows the type of WPBA and horizontal axis (X Axis) is number of participants

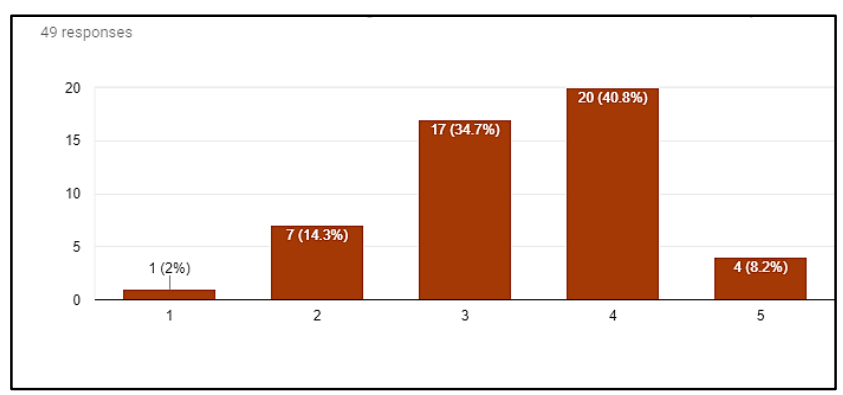

Fig. 2: Response to question no 6- The WPBA is time consuming it is not feasible in the clinical set up, on Likert scale $\mathrm{X}$ axis (horizontal) :1- strongly agree; 2- Agree; 3- May be neutral ; 4- Disagree; 5- strongly disagree. $\mathrm{Y}$-axis (vertical) indicates number of participants.

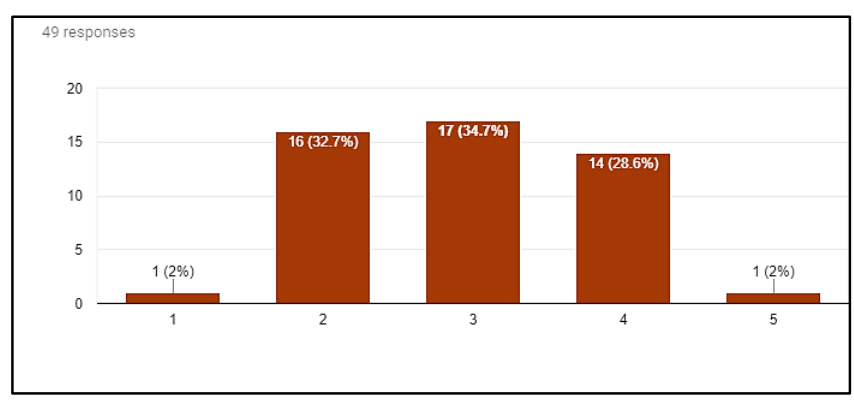

Fig. 3: response to Question no 7: Teachers may not cooperation for increase in workload." on Likert's scale (X axis), on $\mathrm{Y}$ axis number of participants



Fig. 4: response to question 8- "The student's will definitely like the WPBA." On X axis shows Likert's scale, Y- axis indicates number of participants. 


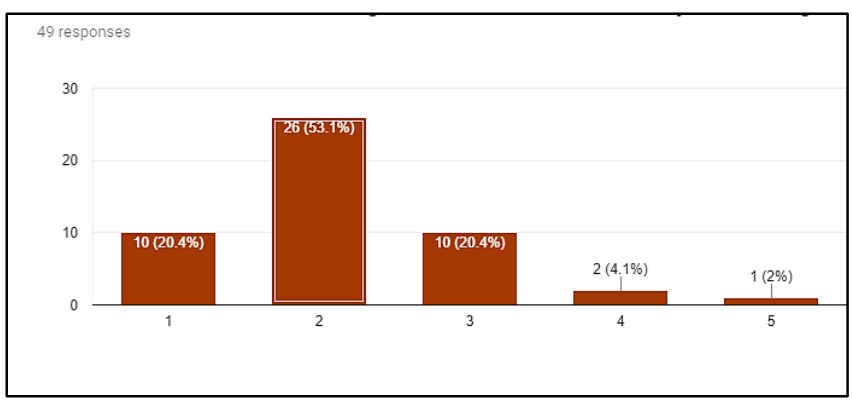

Fig. 5: Response to Question 9: "The WPBA is useful for undergraduate students clinical subjects training." $\mathrm{X}$ axis shows the Likert's scale and Y axis, number of participants

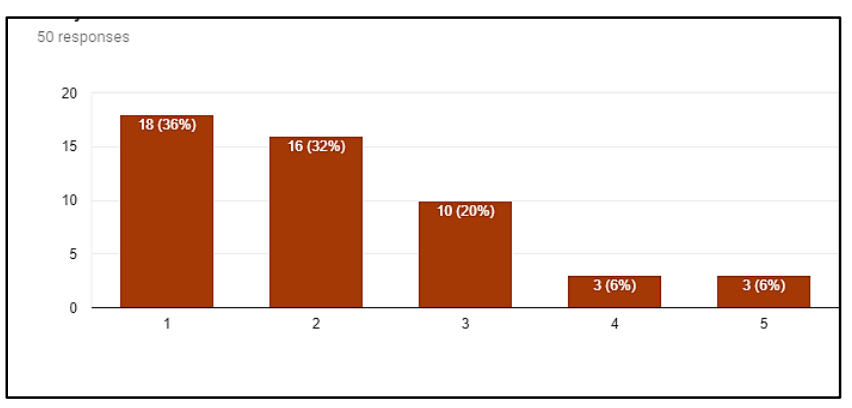

Fig. 6: Response to question 10: "The WPBA is beneficial to post graduate students of clinical dental subjects." X axis -on Likert scale and $\mathrm{Y}$ axis indicates number of participants

\section{Discussion}

Going through the literature the application of WPBA is seen in the UK dental universities back in 2007. The other universities world-wide has used it for the formative assessment of the undergraduate dental students and specifically for dental postgraduates. ${ }^{2}$

The need of WPBA tool, their implementation and evaluation of the tool implemented in dental training are already mentioned in the published data.

Grieveson B ${ }^{4}$ et al (2011) conducted a study with trainers and trainees in Merseyside, UK, investigated the perceived effectiveness of workplace based assessments (WPBAs) used in the Committee of Postgraduate Dental Deans and Directors' (COPDEND) foundation training portfolio. They concluded that both trainers and trainees highlighted the value of WPBAs in providing feedback and insight into the developmental needs of young practitioners. This study also reported positive feedback on the WPBA tools that trainers felt were easy to use and provided a clear and comprehensive record of progress through the training year.

Kirton $\mathrm{JA}^{5}$ et al (2013) evaluated the effectiveness of WPBAs in the UK wide national scheme and explore potential areas for development, ensuring a standardised delivery of the foundation training curriculum, assessment of progress and competence. This study confirmed the findings of pilot study by Grieveson et al in that WPBAs were acceptable and effective in providing feedback and insight into young practitioners developmental needs. However, it also raised a number of issues with regard to their effectiveness and delivery as part of a national training scheme. The overall consensus from both trainees and trainers was very positive regarding the use of D-EPs, some negative comments and concerns were raised. These related mainly to lack of standardisation of procedures assessed and the necessity for training and calibration of assessors. Over $25 \%$ of trainers reported that they had received no formal training. Case-based discussions were felt by both trainers and trainees to be the most beneficial of the WPBAs in providing feedback for the trainees developmental needs and improving patient care.

Training dental students at graduate and post graduate levels involve a lot of clinical procedural skills. There is a need to have competency based dental education. Using various WPBA appropriately as a formative assessment can improve the standard of education. The WPBA with is feedback as an educational tool can have a positive effect. The Dental faculties being one of the stake-holders, their knowledge and attitude towards this type of tool is deemed essential. The author has conducted this survey keeping this in mind. The questionnaire tool focuses on the awareness of dental faculty about WPBA, their opinion about it. For those unaware of this tool the details of WPBA is mentioned in the survey document. This research confirmed that $64 \%$ teachers knows about it, $51 \%$ knew through the HSET (healthcare education technology) workshops. But $70 \%$ mentioned that it is not practised in the routine education. According to participants DOPS and minicex being the most beneficial for dental education. Participates don't think its time consuming. In their opinion the students may like it. In addition participants feel that WPBA is beneficial for both undergraduates as well as postgraduates.

\section{Conclusion}

The results from this survey confirms the positive attitude of the dental faculties towards WPBA. The perception of participants is it will be useful tool for UG as well as PG formative assessment.

There is a need to carry out the pilot multicentric studies for implementing WPBA involving the other higher stakeholders. This will focus on the possible problems in the WPBA implementation, their acceptance by trainers and trainees, the positive as well as negative impact. The incorporation of these specific assessments in the curriculum and university syllabus is necessary for its uniform implementation. The hands-on training to the faculties is essential.

\section{Source of Funding}

None.

\section{Conflict of Interest}

None.

\section{References}

1. Norcini J, Burch V. Workplace-based assessment as an educational tool: AMEE Guide No.31. 2007;29:855-71.

2. Manekar V S. workplace based assessment (WPBA) in dental education- a review. J Educ Technol Health Sci. 2018;5(2):805. 
3. Singh T, Modi JN. Workplace-based assessment: a step to promote competency based postgraduate training. Indian Pediatrs. 2013;50(6):553-9.

4. Grieveson B, Kirton JA, Palmer NO, Balmer MC. Evaluation of workplace based assessment tools in dental foundation training. Br Dent J. 2011;211:E8.

5. Kirton JA, Palmer NO, Grieveson B, Balmer MC. A national evaluation of workplace-based assessment tools (WPBAs) in foundation dental training: A UK study. Effective and useful but do they provide an equitable training experience? $\mathrm{Br}$ Dent J. 2013;214(6):305-9.

How to cite: Manekar VS. The attitude and perception about need of WPBA in Dental education among the senior faculties of Dental Institutes of Central India- cross-sectional study. J Educ Technol Health Sci. 2020;7(1):25-8 